\title{
Effectiveness of Webinar based Teaching for Physiotherapy Interns during COVID- 19 in India- A Pilot Study
}

\author{
jitender Munjal', Kalpana Zutshi
}

${ }^{1}$ Physiotherapist,(North DMC Medical college\& Hindu Rao Hospital, Delhi); PhD Scholar Jamia Hamdard, New Delhi, India. ${ }^{2}$ Associate Professor, F/o AHS, Department of Rehabilitation Sciences, Jamia Hamdard University, New Delhi, India. DOI: https://doi.org/10.24321/2394.6539.202015

\section{I $\quad \mathbf{N} \quad \mathbf{F} \quad \mathbf{O}$}

\section{Corresponding Author:}

Kalpana Zutshi, Department of Rehabilitation Sciences, Jamia Hamdard University, New Delhi, India.

E-mail Id:

zutshi.kalpana@gmail.com

Orcid Id:

https://orcid.org/0000-0002-3270-8068

How to cite this article:

Munjal J, Zutshi K. Effectiveness of Webinar based Teaching for Physiotherapy Interns during COVID-19 in India- A Pilot Study. J Adv Res Med Sci Tech 2020; 7(4): 3-7.

Date of Submission: 2020-12-01

Date of Acceptance: 2020-12-18

\section{$\begin{array}{llllllll}\mathbf{A} & \mathbf{B} & \mathbf{S} & \mathbf{T} & \mathbf{R} & \mathbf{A} & \mathbf{C} & \mathbf{T}\end{array}$}

Introduction: SARS Covid II pandemic has consistently spread and has severely disrupted the lives of more than the three quarters of the world's population. Their system is unable to effectively respond to the current challenges in the present day pandemic, which has put forth another challenge for medical educators across the world to deal with the huge responsibility of rethinking how to carry on delivering high quality medical education due to social isolation strategies and enormous clinical responsibilities. Webinars have become an essential component of Physiotherapy teaching during the pandemic periods. Lecturers have reported about satisfaction and enjoyable sessions during webinars.

Materials and Method: An intern's physiotherapy attitude form, student's satisfaction questionnaire, smooth delivery and intuitive interface scores were dependent variables and Teaching Method (participation in a webinar or classroom teaching) is the independent variable.

Result: Descriptive analysis and Students t-test were done for inter-group comparison of Webinar Group Vs Classroom group which were found to be statistically significant at $p \leq 0.5$. The scores for Webinar group vs Classroom group respectively are Physiotherapy attitude questionnaire Test scores $\left(54.17 \pm 8.8 \& 39.38 \pm 10.8, t=5.7^{*}\right)$, Student's satisfaction questionnaire scores $(4.54 \pm 0.59 \& 4.29 \pm 0.69, t=1.45)$, Smooth Delivery Scores $(4.5 \pm 0.5 \& 5.0 \pm 0, t=4.79 *)$, Students intuitive interface scores $\left(4.63 \pm 0.4 \& 3.04 \pm 0.2 \quad \mathrm{t}=13.2^{*}\right)$ and Action taken scores $(4.58 \pm 0.4 \&$ $3.25 \pm 0.43, \mathrm{t}=11.56 *)$.

Conclusion: The webinar based teaching is more effective as compared to classroom teaching for Physiotherapy Interns with a limitation to teaching practical skills especially in fields like Physiotherapy where it is essential.

Keywords: Webinar Group, Classroom Group, Physiotherapy Attitude, Student's Satisfaction, Smooth Delivery Scores, Students intuitive Interface and Action taken 


\section{Introduction \& Literature Review}

Over the last nine months, SARS Covid II pandemic has consistently spread across the world. It has severely disrupted the lives of more than the three quarters of the world's population that reside in Low and Middle Income Countries (LMIC) like India and in Latin America, South East Asia and Sub-Saharan Africa which have not previously developed healthcare and medical education systems. ${ }^{1}$ Their system is unable to effectively respond to the current challenges in the present day pandemic.

The combination of high population, health demand and insufficient resources, with very few skilled health professionals and medical educators was already a challenge even prior to this pandemic in developing countries like India. The COVID-19 pandemic has put forth another challenge for medical educators across the world to deal with the huge responsibility of rethinking how to carry on delivering high quality medical education at a time when medical schools are closing face to face teaching due to social isolation strategies and educators have to cope with their enormous clinical responsibilities. This pandemic situation has made all the educational schools and colleges across the world to take up online teaching as a resort to counter the pandemic situation. ${ }^{2}$ The Courses are conducted online, examinations are being carried out online and assignments are being submitted via email.

Webinars are defined as web based seminars, in which participants and facilitators communicate live over internet across the globe using shared virtual platforms and interact ubiquitously and synchronously in real time via voice over Internet Protocol (IP) technology and webcam equipment. It is also known as online distant teaching learning method. ${ }^{3}$ Medical webinar is application and usage of medical course, seminars, and conferences, workshops in Medical and Paramedical webinars in the field of education. ${ }^{4,5}$ Webinars have become an essential component of Physiotherapy teaching during the pandemic periods. ${ }^{6}$ Tutors, students and lecturers have reported about satisfaction and enjoyable sessions during webinars. ${ }^{7-14}$ However, the experience of the educators has not been analyzed. The study focuses at the effectiveness of webinar based teaching for physiotherapy interns and their professional training in India. In the context of Physiotherapy, the study tried to analyze how effective are webinars in physiotherapy in promoting student achievement in terms of knowledge performance in test and which characteristics moderate student achievements by the feedback forms filled by the subjects before and after the sessions which is one of the methods to measure the quality of the webinar. Various kinds of feedback forms have already been introduced in Education system. ${ }^{15}$ Webinar based teaching learning programs provide a great opportunity for practicing physiotherapists to interact with pioneers in the field of Physiotherapy and provide good quality updated treatment to patients. Nambi et al. ${ }^{6}$ have studied the effects of webinar based teaching program on therapists' attitude and satisfaction of Low Back Pain (LBP) patients and found wide positive effects on quality of life and patients satisfaction.

\section{Material and Method}

\section{Experimental Study}

Randomized controlled crossover study design with repeated measures.

An intern's Physiotherapy attitude form in terms of (knowledge, assessment and performance), student's satisfaction questionnaire, smooth delivery and intuitive interface scores were the Dependent Variables and Teaching Method (participation in a webinar or classroom teaching) is the Independent Variable.

\section{Participants}

Interns in Department of Physiotherapy, Hindu Rao hospital, Delhi, India.

\section{Inclusion Criteria and Exclusion Criteria}

- Interns in Physiotherapy, who signed informed consent were included

- $\quad$ Both sexes were included

- The subjects who had previous knowledge (pretest score $>30 / 100$ ) about the musculoskeletal and sports conditions being taught in the present study were excluded

- The subjects who had computer equipment related issues were also excluded from the study

Out of the population of thirty interns, a total of twenty four (24) interns (14 females and 10 males) (Mean age 22.17 \pm 0.78 years) participated in the webinar-based study after taking an informed consent that excluded 2 male dropouts.

\section{The Study was Divided into Two Steps ${ }^{5,6}$}

In the first step, the interns were divided equally in two groups: Group A (7 females and 5 males) and Group B (7 females and 5 males) by randomization of male and female subjects separately. The two groups were taught through six webinar sessions and six classroom sessions of 45 minutes duration each by the two authors equally on musculoskeletal and sports conditions diagnosis and management. The subjects were given a pretest objective test and the pretest performance score were noted before the start of each session. The Group A was taught six classroom sessions followed by six webinar sessions and Group B was taught six webinar sessions followed by six classroom sessions to act as controls and nullify the order effect. The subjects were later subjected to knowledge or performance tests with objective test scores after the sessions as a post test measure. The feedback form also had scales to measure the content satisfaction, smooth delivery, Intuitive interface 
and action taken on the Likert scale with scores ranging from 1 to 5 (least to max).

The study was carried out over a period of 3 months (May, June and July 2020). The Webinar technology was Zoom and Cisco WebEx Webinars and face to face lecture was held for classroom teaching. The subjects were asked to fill up an evaluation sheet that comprised of feedback and an objective type test of 20 questions of 5 marks each before and after the session.

In the second step, the data collected from feedback forms after the teaching via webinar and after classroom teaching was compiled and analyzed. The means of the pretest and post test scores was calculated. The results were taken up as Two Groups of participants (Group 1 or Webinar group and Group 2 or Classroom group) where all the 24 participants were subjected to 6 webinar sessions and 6 classroom sessions respectively.

The results were analyzed using paired T-test in SPSS (version 25 ) software with a $p$-value $\leq 0.05$ as significant.

\section{Result}

The results of the study showed that the 24 interns had a Mean age $(22.17 \pm 0.78)$ years. The median age was 22 years and modal age was 22 years. Amongst all the subjects, 58.33 $\%$ were females and $41.67 \%$ were males. The results are presented as mean and standard deviation of scores for Physiotherapist's Attitude test, student's satisfaction, smooth delivery of lecture, intuitive interface and action taken.

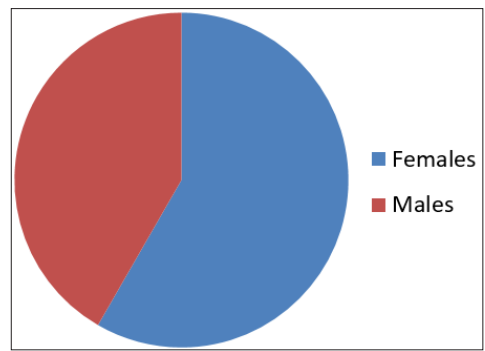

Figure I.Pie chart showing percentage of male and female subjects recruited for the study

Table I.Inter group comparison of various variables of Subjects in two groups viz Webinar group (Grp I) and Classroom group ( Grp 2)

\begin{tabular}{|c|c|c|c|c|}
\hline Variables & Group & \begin{tabular}{|c|} 
Mean \\
difference \\
$\pm S D$
\end{tabular} & $\begin{array}{c}\mathrm{t}- \\
\text { value }\end{array}$ & $\begin{array}{c}\text { p- } \\
\text { value }\end{array}$ \\
\hline \multirow{2}{*}{$\begin{array}{l}\text { Physio- } \\
\text { therapy } \\
\text { attitude } \\
\text { questi- } \\
\text { onnaire } \\
\text { Test scores }\end{array}$} & $\begin{array}{l}\text { Webinar } \\
\text { group } \\
\text { (Grp1) }\end{array}$ & $54.17 \pm 8.8$ & 5.7 & $0.01 * *$ \\
\hline & $\begin{array}{l}\text { Classroom } \\
\text { group } \\
\text { (Grp2) }\end{array}$ & $39.38 \pm 10.8$ & & \\
\hline
\end{tabular}

\begin{tabular}{|c|c|c|c|c|}
\hline \multirow{2}{*}{$\begin{array}{l}\text { Student's } \\
\text { satisfaction } \\
\text { questi- } \\
\text { onnaire } \\
\text { scores }\end{array}$} & $\begin{array}{l}\text { Webinar } \\
\text { group } \\
\text { (Grp1) }\end{array}$ & $4.54 \pm 0.59$ & 1.45 & 0.08 \\
\hline & $\begin{array}{l}\text { Classroom } \\
\text { group } \\
\text { (Grp2) }\end{array}$ & $4.29 \pm 0.69$ & & \\
\hline \multirow{2}{*}{$\begin{array}{c}\text { Smooth } \\
\text { Delivery } \\
\text { Scores }\end{array}$} & $\begin{array}{l}\text { Webinar } \\
\text { Group } \\
\text { (Grp1) }\end{array}$ & $4.5 \pm 0.5$ & 4.79 & $0.05^{*}$ \\
\hline & $\begin{array}{l}\text { Classroom } \\
\text { group } \\
\text { (Grp2) }\end{array}$ & $5.0 \pm 0$ & & \\
\hline \multirow{2}{*}{$\begin{array}{l}\text { Students } \\
\text { intuitive } \\
\text { interface } \\
\text { scores }\end{array}$} & $\begin{array}{c}\text { Webinar } \\
\text { group } \\
\text { (Grp1) }\end{array}$ & $4.63 \pm 0.4$ & 13.2 & $0.01 *$ \\
\hline & $\begin{array}{c}\text { Classroom } \\
\text { group } \\
\text { (Grp2) }\end{array}$ & $3.04 \pm 0.2$ & & \\
\hline \multirow{2}{*}{$\begin{array}{l}\text { Action } \\
\text { taken } \\
\text { scores }\end{array}$} & $\begin{array}{l}\text { Webinar } \\
\text { group } \\
\text { (Grp1) }\end{array}$ & $4.58 \pm 0.4$ & 11.56 & $0.01 * *$ \\
\hline & $\begin{array}{l}\text { Classroom } \\
\text { group } \\
\text { (Grp2) }\end{array}$ & $3.25 \pm 0.43$ & & \\
\hline
\end{tabular}

( $p$-value > 0.05 Non Significant; $p$-value $\leq 0.05^{*}$ Significant; $p$-value $\leq 0.01 * *$ Highly Significant).

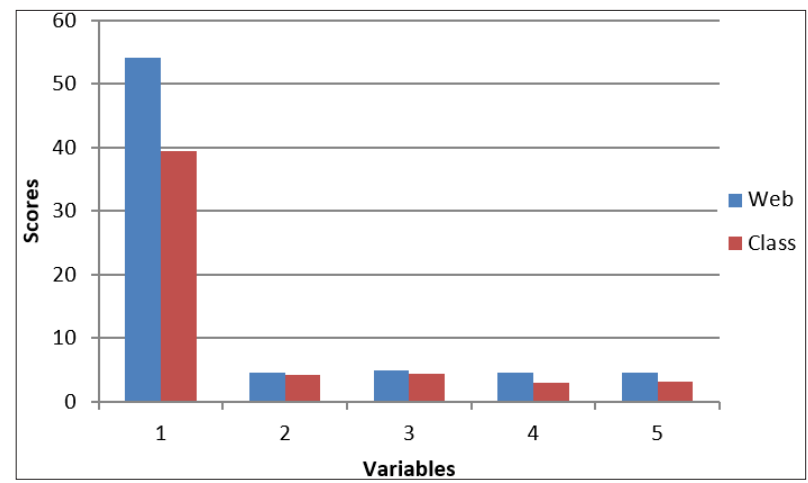

Figure 2.Inter group comparison of various variables of Subjects in two groups viz Webinar group (Grp I) and Classroom group ( Grp 2)

\section{Variables}

1. Physiotherapy attitude questionnaire Test scores

2. Student's satisfaction questionnaire scores

3. Smooth Delivery Scores

4. Students intuitive interface scores

5. Action taken scores

\section{Discussion}

The results of the study show that there is a statistically significant difference in Physiotherapy attitude questionnaire 
scores of the interns in Webinar teaching and classroom teaching group and the results are in concurrence with the study of meta analyses and systemic review by Gegerfurtner et al. ${ }^{15}$ in 2020 which shows a very trivial increase in the students attitude. The subjects have more interest and inclination towards technology based learning and the short duration of about 45 minutes session generates interest, focuses attention and concentration. The study is in contradiction to the results of a systemic review by Yao-Ting sung et al. ${ }^{16}$ which shows that mobile learning research applies laggard methodologies in education. The student satisfaction scores showed a statistically nonsignificant result in intergroup comparison of the webinar and classroom based learning groups. This may be due to the fact that the students found the technology based teaching to be handy, convenient and interest generating and were attentive and alert to capture the content the same way as they were during the face to face classroom teaching. The results are in concordance with the study by Nambi et al. $(2020)^{6}$ where the patients are well satisfied by the therapists trained by webinar based teaching for treatment of low back pain.

The Internet technology, with Digital India in progress has tried to ensure that the webinar based teaching runs smoothly but the participants did face some difficulty in attending online classes on Zoom and Cisco Web Ex smooth delivery and student's interface results show a statistically significant difference in intergroup comparison for webinar based teaching and classroom teaching group with $P$ value $\leq 0.05 .{ }^{17}$ The students are so tech savvy now a days that the result also showed a statistically significant value for intergroup comparison for intuitive interface for both the groups. The student's expectations regarding the lectures during the pandemic phase were well met and so the mean scores were higher for the webinar group. The students were most probably reluctant in attending the classroom lectures during the pandemic due to the social distancing norms.

The action taken scores show that the students are more interested and have a positive affinity towards the webinar based teaching as the webinar group shows a higher statistically significant action taken score in comparison to the classroom teaching score with $p<0.001$. The results may be attributed to the fact that with the advancement of technology, cheap data availability, convenience, cost cutting on transport and saving of time which are the potential benefits of online learning as described by Appanna et al. ${ }^{18}$ and especially in the phase of COVID-19 era where Physical distancing is the key to avoid the spread of the Pandemic, is one of the positive outcomes of webinar based teaching and this is in concurrence with the results of study by Nambi et al., $2020 .^{6}$
In India, it is an excellent opportunity to improve the internet connectivity throughout rural areas and step ahead towards Digital India. All the rural and urban areas in India may be connected digitally for a fruitful interaction amongst the teachers and the students. It is pertinent to mention here that the practical skills of the Physiotherapy interns involving touch and palpation could not be taught and assessed and may be a limitation of the study especially in fields like Physiotherapy where it is essential.

\section{Conclusion}

The results of the study showed that the webinar based teaching is more effective as compared to classroom teaching for Physiotherapy Interns during the pandemic period with a limitation to teaching practical skills.

\section{Conflicts of Interest: None}

\section{References}

1. Dario Cecilio Fernandes DC, Maria Cândida Ribeiro Parisi MCR, Thiago MS, Sandars J. The COVID-19 pandemic and the challenge of using technology for medical education in low and middle income countries Publish. MedEd Teaching and Learning, Technology 2020. DOI: https://doi.org/10.15694/mep.2020.000074.1.

2. McKimm J, Gibbs T, Bishop J, Jones P. Health Professions' Educators' Adaptation to Rapidly Changing Circumstances: The Ottawa 2020 Conference Experience'. MedEdPublish 2020; 9. DOI:https://doi. org/10.15694/mep.2020.000047.1.

3. Sura K, Lischalk JW, Leckie J, Welsh JS, Mundt AJ, Fernandez E. Webinar-Based Contouring Education for Residents. J Am CollRadiol 2017; 14(8): 1074-1079.

4. Eric C, Buxton, Erik C, Burns, James E, De Muth. Professional Development Webinars for Pharmacists. Am J Pharm Educ 2012; 12; 76(8): 155.

5. Ellias JL, Merriam SB. Philosophical Foundations of Adult Education. Malabar, FL: Krieger, 2005.

6. Nambi G, Abdelbasset W K, Abodonya A, Saleh A K, Khanam $\mathrm{H}$. Effects of webinar based teaching program on therapists' attitude and satisfaction of LBP patients. Arch Pharma Pract 2020; 11(1): 122-128.

7. Goe R, IpsenC, Bliss S.Pilot testing a digital career literacy training for vocational rehabilitation professionals. Rehabilitation Counseling Bulletin 2018; 61: 236-243.

8. Häkkinen $P$, Järvelä $S$. Sharing and constructing perspectives in web-based conferencing. Computers \& Education 2006: 47: 433-447. DOI: https://doi. org/10.1016/j.compedu.2004.10.015 .

9. McKinney WP. Assessing the evidence for the educational efficacy of webinars and related internetbased instruction. Pedagogy Health Promotion: The Scholarship of Teaching and Learning, 2017; 3: 475-515. DOI: https://doi.org/10.1177/2373379917700876 . 
10. Mc Mahon Howard J, Reimers B .An evaluation of a child welfare training program on the commercial sexual exploitation of children (CSEC). Evaluation and Program Planning 2013; 40: 1-9. DOI: https://doi.org/10.1016/j. evalprogplan.2013.04.002 .

11. Nelson LS. Learning outcomes of webinar versus classroom instruction among bacca laureate nursing students: A randomized controlled trial. Denton,TX: Unpublished doctoral dissertation, Texas Woman's University, 2010.

12. Olson JS, McCracken FF. Is it worth the effort? The impact of incorporating synchronous lectures into an online course. Online Learning Journal 2015; 19: 73-84. https://doi.org/10.24059/olj.v19i2.499.

13. Stout JW, Smith K, Zhou C, Solomon C, Dozor AJ, Garrison $\mathrm{MM}$ etal. Learning from a distance: Effectiveness of online spirometry training in improving asthma care. Academic Pediatrics 2012; 12: 88-95. DOI:https://doi. org/10.1016/j.acap.2011.11.006.

14. Wang SK, Hsu HY. Use of the webinar tool (Elluminate) to support training: The effects of webinar- learning implementation from student- trainers' perspective. The Journal of Interactive Online Learning, 7,175-194, cited in A. Gegenfurtner and C. EbnerEducational Research Review 2008; 28 (2019): 10029319.

15. Gegenfurtnera A, Ebnerb C. Webinars in higher education and professional training: A metaanalysis and systematic review of randomized controlled trials 2019. DOI: https://doi.org/10.1016/j.edurev.2019.100293.

16. Tseng JJ, Cheng YS, Yeh HN. How pre-service English teachers enact TPACK in the context of web-conferencing teaching: A design thinking approach. Computers \& Education 2019; 128: 171-182. DOI: https://doi. org/10.1016/j.compedu.2018.09.022.

17. Bernard RM,Abrami PC, Borokhovski E, Wade CA, Tamim RM, Surkes MA etal. A meta-analysis of three types of interaction treatments in distance education. Review of Educational Research 2009; 79: 1243-1289.

18. Appanna, Subhashni. A Review of Benefits and Limitations of Online Learning in the Context of the Student, the Instructor and the Tenured Faculty. International Journal on E-Learning 2008; 7: 309333844, 2008. https://doi.org/10.3102/0034654 . 